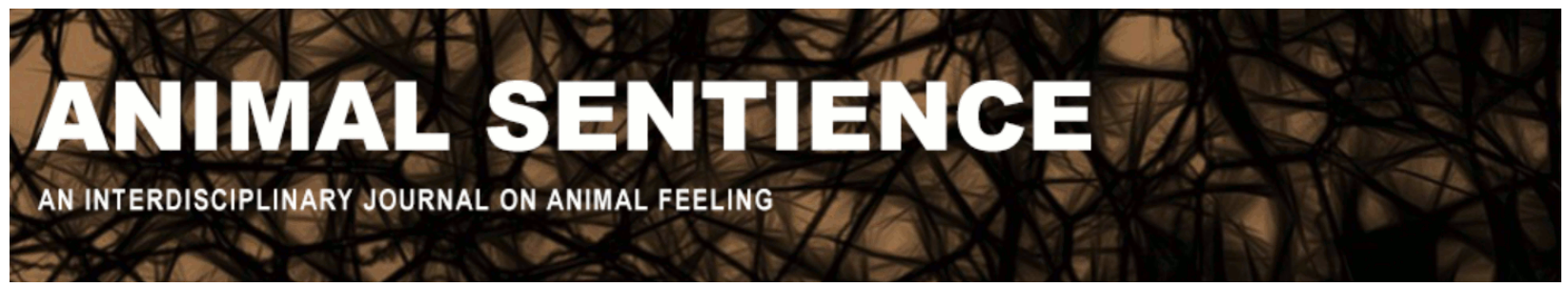

Rowlands, Mark (2016) Are animals persons?. Animal Sentience 10(1)

DOI: $10.51291 / 2377-7478.1110$

Date of submission: 2016-06-03

Date of acceptance: 2016-07-12

(c) (i)

This article has appeared in the journal Animal

Sentience, a peer-reviewed journal on animal

cognition and feeling. It has been made open access,

free for all, by WellBeing International and deposited

in the WBI Studies Repository. For more information,

please contact

wbisr-info@wellbeingintl.org.

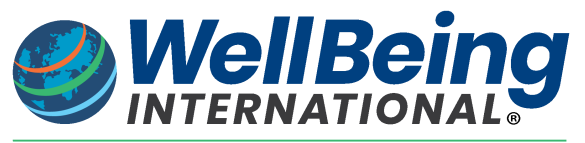

SOLUTIONS FOR PEOPLE, ANIMALS AND ENVIRONMENT 
Call for Commentary: Animal Sentience publishes Open Peer Commentary on all accepted target articles. Target articles are peer-reviewed. Commentaries are editorially reviewed. There are submitted commentaries as well as invited commentaries. Commentaries appear as soon as they have been revised and accepted. Target article authors may respond to their commentaries individually or in a joint response to multiple commentaries.

Instructions: http://animalstudiesrepository.org/animsent/guidelines.html

\title{
Are animals persons?
}

\author{
Mark Rowlands \\ Department of Philosophy, University of Miami
}

\begin{abstract}
It is orthodox to suppose that very few, if any, nonhuman animals are persons. The category "person" is restricted to self-aware creatures: humans (above a certain age) and possibly some of the great apes and cetaceans. I argue that this orthodoxy should be rejected, because it rests on a mistaken conception of the kind of self-awareness relevant to personhood. Replacing this with a sense of self-awareness that is relevant requires us to accept that personhood is much more widely distributed through the animal kingdom.
\end{abstract}

Keywords: animals, John Locke, meta-cognition, mirror test, persons, self-awareness

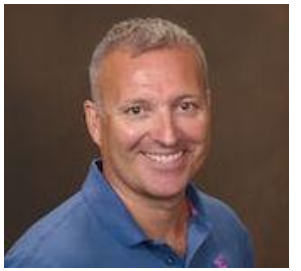

Mark Rowlands is Professor of Philosophy at University of Miami. He studies the philosophy of mind, ethics and moral psychology. Mark has written 18 books, including Animal Rights (Macmillan 1998), The Environmental Crisis (Macmillan, 2000), Animals Like Us (Verso, 2002), The Philosopher and the Wolf (Granta, 2008), and Can Animals be Moral? (Oxford, 2012). http://www.as.miami.edu/phi/people/

\section{Persons: The Lockean Conception}

The notion of personhood encompasses three quite different ideas. An individual qualifies as a legal person if its status as such is enshrined in law. The great ape personhood movement has, in some jurisdictions, achieved some success in having the great apes recognized as persons, or as having at least some of the rights associated with persons. ${ }^{1}$ The legal sense of personhood is not the focus of this target article. Whether or not the law is willing to recognize an individual formally as a person depends partly, but essentially, on the vicissitudes of social and legal history. ${ }^{2}$ Sometimes the concept of a person is defined in explicitly moral terms: a person is the sort of thing to which a certain sort of moral consideration is owed. To claim that an individual is a moral person is to claim that it has a certain kind of distinctive moral status: a status that cannot (or is unlikely to) be had by something that is not a person. This target article is not concerned with the moral sense of 
person either. Rather its focus will be what we might, for want of a better word, call the metaphysical conception of the person - where the term "metaphysical" should be understood in its traditional sense as "pertaining to what something is." An individual is a person in the metaphysical sense if (and only if) it has certain (non-moral, non-legal) features: features that confer on it the status of a person.

When the question of personhood in animals arises, discussion is often based on a certain conception of what these person-conferring features would have to be. This conception derives (knowingly or unknowingly) from John Locke's famous definition of a person as, "a thinking intelligent being, that has reason and reflection, and can consider itself the same thinking thing, in different times and places." (1690: 280). Animals, it is widely thought, do not satisfy the conditions specified by Locke - certainly not all of these conditions.

According to Locke's definition, a person is thought to comprise two (allegedly) distinguishable components: (1) a mental life, and (2) unity. A person must not only have various mental states and processes (those processes involved in being a subject of mental states, and processes such as "thinking," "intelligence," "reason," and "reflection"), but these states and processes must also form a unified whole (the "same thinking thing"). A series of disjointed and disassociated mental states and processes would not form a person. For a person to exist, it is necessary that these be somehow bound together into a single, coherent, unity. Locke also provides a suggestion about what might constitute this unity: While the mental life that is to be unified may, in principle, admit of varying degrees of complexity, it must include the ability of the person to "consider itself the same thinking thing, in different times and places." With this ability, one can recognize mental acts and processes that make up a mental life as belonging together to the same thinking thing. And this, it might be assumed, is the unifying factor that binds this mental life into a single whole.

To recognize oneself as the same thinking thing is one form that self-awareness can take. Thus, the Lockean conception ties the issues of personhood and self-awareness closely together. Self-awareness, in some form at least, is a necessary condition of personhood. In this paper, I shall assume that this is so. If animals are not self-aware, they are not persons. However, the idea of self-awareness encompasses a number of distinct ideas, and which one (or ones) is pertinent to personhood is, as yet, unclear. Thus, much turns on how, precisely, we should understand the term "consider" as it features in Locke's definition. I shall argue that this term can be understood in two very different ways, yielding two very different conceptions of the person.

I shall argue for the following four claims: (1) Broadly speaking, self-awareness bifurcates into two importantly different forms. ${ }^{3}$ (2) Although there is little evidence for the claim that animals have the first of these forms of self-awareness, there are very good reasons for supposing that they have the second. ${ }^{4}$ (3) It is this second form of self-awareness - the form that many animals can have - that is crucial to the question of personhood. Thus, I shall argue that (4) at least some animals can be persons because (4a) they have a mental life and (4b) are aware of this mental life in the sort of way that can confer the requisite unity upon it. 


\section{Reflective Self-Awareness}

Thoughts, beliefs, desires, hopes, fears, and expectations are all examples of what philosophers call intentional states or acts. This means, simply, that they are about something. According to a common way of thinking about such acts, a thought, belief, etc. is about an object precisely to the extent that it "presents" this object in some way or other. Suppose, following Kaplan (1989), I see a reflection in the shop window of a man whose pants are on fire. I think, “That man's pants are on fire!” For my thought to be about the man, it is necessary that I represent him in some way - in this case as that man. I might, of course, represent him in some other way - as, for example, when I realize that $I$ am the man reflected in the window, and I come to think, "My pants are on fire!" The way the object is presented is often called the mode of presentation of the object. Thus, on a standard way of thinking about intentional acts, it is common to distinguish three components: (i) the intentional act itself (in this case, the act of thinking), (ii) the intentional object of that act (the man whose pants are on fire), and (iii) the mode of presentation of that object (that man, me, etc.).

Reflective accounts of self-awareness, as I shall use this term, understand such awareness in terms of this general picture of intentionality. In this case, the object of the self-awareness might be one of two things. It might be something bodily: one's body, or part thereof, or an event occurring in this body, and so on. Or, it might be something mental: a (first-order) mental state of some sort. Whatever this object is, self-awareness consists of an intentional act directed towards it. Accounts differ about the nature of this act. Some accounts think of it as quasi-perceptual, others think of it as cognitive - typically, an act of thinking. I do not need to take a stand on this issue. What unites both accounts is the general idea that selfawareness consists of an intentional act directed to some bodily or mental object. For this to occur, the object must be presented in some way. For example, the body might be presented as mine (or as a body that has seen better days, and so on). A mental state - a desire or realization, for example - might similarly be presented as mine: as a mental state that I currently have or am undergoing. Or it might be presented in some other way (as troubling, perplexing, etc.).

The reflective model of self-awareness provides one clear way of interpreting what is going on when a subject, in Locke's sense, "consider[s] itself the same thinking thing, in different times and places." There is first the intentional act - considering, which we can understand as a type of thinking or recognition. There is, second, the object of the act - itself. And there is, third, the mode of presentation of this object: the same thinking thing.

If we interpret in this way the idea expressed in "considering," two things follow. First, most - but not all - humans are persons in this sense. Second, and more important for our purposes, we arrive at an orthodox view, shared by almost all philosophers and scientists: very few, if any, nonhuman animals (henceforth, "animals") are persons in this sense. Until relatively recently this failure of animals to qualify as persons might have been traced to their (supposed) lack of a mental life: much of the twentieth century was characterized by a reluctance to accord any sort of mental life to animals. But this reluctance has slowly melted 
away over the last four decades or so. Today, it is far more common to suppose that the reason animals do not qualify as persons is that (a) they lack self-awareness - where this is understood in terms of the standard model of intentionality outlined above - and that (b) without this self-awareness whatever mental lives they have lack the requisite unity for them to qualify as persons. That is, animals do not qualify as persons because of their (alleged) inability to make themselves - whether their bodies or their mental lives - into objects of their (higher-order) intentional acts. As the object of such an act might be bodily or mental, this inability is traced to two alleged deficits: (1) the failure of most animals on the mirror self-recognition (MSR) test, and (2) the absence of meta-cognition in most or all animals.

\section{Mirror Self-Recognition}

The fiftieth anniversary of Gordon Gallup's (1970) mirror self-recognition (MSR) test is rapidly approaching. Gallup's work was a seminal contribution to the study of animal minds, and all the more impressive because it occurred at a time when the very idea of animal minds was regarded with hostility or ridicule. Nevertheless, it has helped distort the way we think about the possibility of self-awareness and personhood in animals.

In the mirror test, a mark (typically a dye) is placed on an animal subject, in a position where it is visible only in a mirror. The animal's subsequent behavior in front of a mirror is observed. If the animal engages appropriately with the mark - using the mirror to inspect it, for example - then it is deemed to recognize that the body reflected in the mirror is its own body. Therefore, it is widely thought, the animal is aware of itself. The interpretation of the test remains controversial (Mitchell 2002). Also controversial is the question of which animals pass the test. It is generally accepted that humans over the age of 18-24 months, common chimpanzees, bonobos, and orangutans consistently pass the test (Gallup et al. 2002). Other animals that have been argued to pass the test include elephants, dolphins, and pigeons (and, most recently, manta rays: Ari \& D'Agostino 2016). Gorillas, to be quite frank, have (in general, Koko is an exception) struggled with the test, although this is generally thought to be because they regard eye contact as an aggressive gesture, and so avoid looking at each other's faces (see Andrews 2011).

My concern is not with the legitimacy of the test nor with the question of which animals pass it but rather with the conception of self-awareness implicated in the test. To pass the test, the animals must recognize the body in the mirror as its own body. That is, it must have a thought of the form: "This is me!" - where the demonstrative "this" denotes the reflection in the mirror. Thus, the intentional act (of recognition) is directed towards an object (the body that appears in the mirror) and this object is subsumed under a certain mode of presentation (identical with me). This is a case of reflective self-awareness, in the sense introduced in the previous section. MSR is thus a test for (one form of) reflective selfawareness. 


\section{Meta-Cognition}

Success on the mirror test is generally regarded as a necessary but not sufficient condition for personhood. This too, follows from Locke's definition. Recognition of one's body as one's body in a mirror does not by itself address the unity condition for personhood. For that we need a way of binding a mental life together into a unified whole. Many have thought that this goal can be achieved by appealing to the same sort of apparatus of reflective selfawareness: a mental act directed toward an object under a mode of presentation. That is, what binds a mental life together into a unified whole is the subject's recognition that these mental states all belong together - all belong to it. If so, then for a mental life to form a unity, the individual that instantiates the various states and processes that comprise this life needs not only bodily self-awareness (in the sense tested for by MSR), but also metacognition: the ability to think thoughts about its mental states and processes - including the thought that these various mental states and processes belong together and belong to it. Thus, the individual that has the mental life must have, in addition, further intentional acts directed towards its (first-order) mental states and processes. These first-order states and processes are now the intentional objects of its higher-order intentional states, and are presented under the mode of presentation belonging together and/or belonging to me. The meta-cognitive abilities required for personhood are, therefore, typically understood in terms of the model provided by reflective self-awareness.

The existence of meta-cognitive abilities in animals, however, is open to doubt. Daniel Povinelli and coworkers have leveled what they call the logical problem against any empirical evidence that seems to support the presence of meta-cognitive abilities in animals (Povinelli \& Vonk 2003; Penn \& Povinelli 2007). Any such evidence can be re-interpreted in terms of "behavior-reading." Does a submissive chimp refrain from approaching a cache of food because it believes the dominant chimp has seen the food? This would be a metacognitive interpretation, since it supposes that the submissive chimp has the ability to think thoughts about what the other chimp sees. Or does the submissive chimp refrain from approaching the food cache because it perceives that the dominant chimp was oriented towards - i.e., facing - the cache when the food was first placed there. This would be a behavior-reading interpretation. The submissive chimp requires only the ability to identify behavioral regularities - such as that when a dominant chimp is oriented towards where food is then placed, it is likely to go for it, and to defend it from others.

This "logical problem" is irrelevant to the concerns of this paper; I accordingly take no stand on the question of its legitimacy. ${ }^{5}$ For our purposes it is sufficient to note that if one is impressed with the logical problem, then one is also likely to think that there is little or no evidence for the existence of meta-cognitive abilities in other animals. If one also thinks that meta-cognitive abilities are required for personhood - and this is a standard assumption then one will also think that personhood is restricted to humans above a certain age (for example, above three to four years old, if you believe the false-belief test, Baron-Cohen, Leslie \& Frith 1985). 


\section{5. “Consider," Reconsidered}

Self-awareness is not restricted to reflective self-awareness. It comes in several different forms, one of which is crucial to the arguments of this paper. The possibility of this other form of self-awareness is in fact implicit in Locke's definition of a person. Locke's full definition is: "a thinking intelligent being, that has reason and reflection, and can consider itself the same thinking thing, in different times and places, which it does only by that consciousness which is inseparable from thinking and seems to me to be essential, to it; it being impossible to perceive without perceiving that he does perceive." The claim that it is impossible to perceive without perceiving that one perceives, taken literally, is of course nonsensical. When I see, for example, I do not see my act of seeing. Nor do I see that I see (in the way that I might see, for example, that the book is on the table). Presumably, Locke is using the term "perceiving" as equivalent to "being aware of": when I perceive, I am aware of perceiving. However, it seems implausible to explain this claim using the apparatus of reflective self-awareness. If this apparatus were used, then whenever I perceive, I would need a higher-order intentional state that takes my act of perceiving as its object and presents this act to me under a certain mode of presentation - for example, as something I am currently doing or engaged in. This is implausible on grounds of phenomenology alone. Most of the time I simply get on with perceiving things. There is no suggestion that, from the standpoint of experience, when I do so I must simultaneously be thinking that I am perceiving, or that I am the subject of any other higher-order mental state that is about my perceiving. This does at least suggest that the term "consider," as Locke uses it, should not be understood in higher-order - reflective - terms. There is an alternative available - an alternative that is the subject of this paper. I begin with some considerations for thinking that there is a kind of self-awareness - awareness of one's mental states and processes that does not conform to the intentional model that defines reflective self-awareness. I shall sharpen the case for this form of self-awareness in subsequent sections.

Wittgenstein once remarked: "It can't be said of me at all - except perhaps as a joke - that I know I am in pain" (1953: section 246). Suppose I say, "I know there is a book on the table." This is a standard (or fairly standard - knowing is an atypically factive attitude) intentional act: an act of knowing, an object known (a book), and a mode of presentation of this object (on the table). Someone might legitimately respond: "How do you know this?" And then I could provide them with a list of factors that support my claim: I can see both book and table, the lighting conditions are good, I have not been experimenting with hallucinogens in the recent past, and so on. Suppose, however, that someone questions my claim to know I am in pain. How could I respond? Any attempted response - e.g., "I can feel it!" "It hurts!" etc. - would merely be reiterations of my original claim to be in pain. Supporting reasons here are not independent of the fact that they purport to support. To feel pain is to be in pain, and vice versa. The moral Wittgenstein drew is that knowledge of mental states is very different from knowledge of non-mental things. Knowledge of mental states is not independent of those states: knowing that I am in pain is part of what it is to be in pain rather than a separate act that has my pain as its intentional object. We might put the point this way: whenever we have the familiar tripartite apparatus of (1) intentional act, (2) intentional object, and (3) mode of presentation of that object, the act and object can typically come apart: at the very least, the object can exist without the act. (The book may 
be on the table without my knowing it). Thus, the existence of the object is independent of the existence of the act directed towards it. This sort of independence of act and object is a standard feature of intentional contexts. But it is entirely absent in the case of my knowing that I am in pain.

Wittgenstein's point applies a fortiori if instead of talking about knowing we talk about awareness. I can claim to be aware of the book being on the table and, if I do, my claim can legitimately be met with the question: "How are you aware of that?" ("What makes you think you are aware of that?" or variations on this general theme). There are no (sensible) corresponding questions if my claim concerns my pain. The book being on the table is independent of my awareness of the book being on the table. My being in pain is not independent of my awareness of being in pain. We use the term "awareness" in both cases I am aware of the book being on the table and I am aware of being in pain - but the meaning of this term differs in each case.

The idea of a kind of awareness that cannot be captured in terms of the standard intentional apparatus is also what underlies the idea of being immune to error through misidentification (IEM) (Shoemaker 1968). Some items are immune to error through misidentification, but others are not. I see, to take the earlier example of Kaplan, the reflection of a man in a shop window. The man's pants are on fire. I mistakenly think the man is someone else, when he is in fact me. My body is, in this sort of context at least, not IEM. If I see the reflection of a body, even my own, I can legitimately ask: whose body is this? But if I am in pain, I cannot similarly ask: whose pain is this? Nor can I ask: whose thought, experience, or emotion is this? To have a sensation, thought, experience, or emotion is to be aware that this state is mine. My awareness of my mental states is, in this sense, IEM. My awareness of non-mental things is not IEM. This suggests, strongly, that we are dealing with two different types of awareness.

I shall follow Sartre (1943) and refer to this second kind of awareness as pre-reflective selfawareness. If my tastes ran more to the Kantian, I might have called it transcendental apperception and distinguished it from empirical apperception - which is indeed one form that reflective self-awareness might take. Whatever appellation we choose, it is one thing to realize that the self-awareness might come in two distinguishable forms. It is quite another to understand what those forms are. The idea of reflective self-awareness does, at least, have the virtue of being relatively familiar. But all we know about pre-reflective awareness so far seems to be negative: we have reason for supposing it is not the same as reflective awareness, since it does not conform to the tripartite model of intentional act, object, and mode of presentation. In the following sections, I shall try to be a little more positive.

\section{Perception: Seeing As}

I see a book before me. I see it, precisely, as a book. It is also true, however, that I do not see all of the book, but only the part that is oriented toward me (the front, let us suppose). Nevertheless, I see it as a book, not as a book-façade. This is because the visual presentation of the book has generated certain implicit expectations or anticipations: I anticipate, for example, that if the book were rotated, I would first see the spine, then the back cover of the 
book, and so on. If I saw the object as a book-façade, on the other hand, the series of expectations would be rather different. This is the difference between seeing an object $a s$ a book and seeing it as a book-façade. These anticipations are implicit. I do not need to be consciously thinking them. Indeed, so many and so nuanced are these anticipations that it is doubtful I could consciously think all of them.

I am implicated in many (arguably all) of these anticipations. For example, some of the relevant anticipations involve either my doing something or something being done to the book relative to me. I anticipate that if I were to move a certain distance to the left, the appearance of the book would change in a certain way. And it would change in a somewhat different way if I were to move the same distance to the right. I am also able to anticipate that if the book were to move relative to me, then the appearances it presents would also change in a certain way. Thus, to see these appearances as the appearances of a certain object involves a kind of awareness of myself. It is I, one and the same I, that is implicated in these expectations: if $I$ were to move five meters to the right, if the book were to move relative to $m e$, and so on. This implicit awareness I have of myself is required for me to see these appearances as appearances of a book (rather than as appearances of something else). ${ }^{6}$

This implicit - or transcendental - form of self-awareness cannot be assimilated to the model provided by reflective awareness. If my awareness of myself were reflective, then I would have to be the object of some mental act or other - seeing, thinking, etc. But the object of my awareness, here, is the book rather than myself. It is the book and its appearances that my act of perception is directed towards: these appearances are the objects of my acts of perception. Nevertheless, self-awareness is implicated in seeing these various appearances as appearances of one and the same thing - a book. Therefore, I am aware of myself, but not because I am the object of any mental act such as seeing, thinking, believing, and so on. It is simply not true that whenever I see an object as an object I must be thinking thoughts of the form: If I move here, the appearances will change in this way, and if I move there, they will change in that way, and so on.

Nevertheless, such is the pull of the idea of reflective awareness that an opponent might, at this point, dig in her heels and claim that these thoughts must be there - merely in unconscious form. I know what the opponent is getting at. I am quite happy to accept that these thoughts are there implicitly - and I shall shortly try to explain what this sort of implicit awareness amounts to. But the category of the implicit is not the same as that of the unconscious. There is no reason to suppose that whenever I see an object as an object, my seeing must be grounded in an indefinitely large array of unconscious thoughts and/or other intentional states.

\section{Perception for Action: Affordances}

Much perception is perception for action, and an implicit form of self-awareness is built into this too. Perception for action is perception of the world in terms of the various possibilities it affords for action - whether these possibilities are positive or negative, beneficial or 
harmful. Implicated in experiencing the world in this way is awareness both of one's goals and of one's body.

Let us suppose I walk into a room, spot an empty chair, walk over to it and sit down. In doing so I might have noticed very little about the chair: its color, shape, fabric and construction might have all escaped my notice. What I did notice was one salient fact: it is empty. And because it is empty, it is what we might call sit-able. To put the matter in Gibsonian terms: unlike all the chairs that are occupied, this chair affords sitting upon. It is the affordance I see, and not the other properties of the chair.

Seeing the chair in this way is indexed to a current goal - understood as what one is hoping or intending to do. If my goal in going to the room is to attend a lengthy meeting, then the emptiness and sit-ability of the chair will be central to my experience of it. Suppose, on other hand, I entered the room because I had been instructed to go and fetch the red chair and not any of the others. In such circumstances, my visual experience would have focused on the chair's color. Which features of the world are salient at any given time is a function of the goals in which we are engaged at that time. Thus, implicit in seeing the world in one way rather than another there is often an awareness of the goal that provides the basis of this seeing. It does not seem appropriate to describe one's awareness of this project in reflective terms. It is not as if I must think to myself thoughts of the form: I am entering this room in order to attend a lengthy meeting, and therefore must be on the lookout for empty chairs. My goal therefore need not be an intentional object of any (higher-order) thought on my part - or, at least, there is no reason for supposing it is. Rather, my awareness of my goal, in this case, consists in my seeing the world in terms of certain features rather than others. This is pre-reflective awareness of my goal: I am pre-reflectively aware of my goal in virtue of the fact that certain features of the world rather than others are the objects of my conscious act of seeing.

Seeing the world in this way also involves pre-reflective awareness of my body. Suppose my goal is indeed to find somewhere to sit for a lengthy meeting. It is, therefore, the sit-ability of the chair that is its most salient feature. But that the chair affords sitting is dependent upon my having a body of a certain sort. If I were twelve feet tall, or twelve inches tall, then the chair would not afford sitting. Neither would it afford sitting if I had four legs. To be aware of the affordances of any object - what that object offers, whether for good or for ill is, at the same time, to be aware of my body.

The body of which I am thus aware is very different from the body I see in the mirror - the body I recognize as mine when I pass the mirror test. The body in the mirror is the body as object: something I am aware of when I look at it. When I see the chair as sit-able, I am aware of my body in a quite different way. The body is not the object of my awareness - that object is a certain affordance of the chair. My body, here, is not something I am aware of, but something I am aware with or in virtue of: I am aware of the affordance - the sit-ability - of the chair in virtue of my body being a certain way, having certain properties rather than others. Thus, in being aware of the affordance, I am aware of my body. This is pre-reflective awareness of my body: I am aware of my body in virtue of being aware of something else, where this something else exists in virtue of my body being a certain way. More generally, 
whenever I am aware of certain possibilities afforded by the world - possibilities for action, broadly construed - I am simultaneously pre-reflectively aware of my body. This is so because the body is the vehicle of my action. And, crucially, I am pre-reflectively aware of my body in virtue of certain conscious acts being intentionally directed towards these possibilities-for-action in the world. Thus, built into this specific intentional act directed towards the world - in this case, a visual act directed towards an affordance of an object - is a pre-reflective awareness of my body. This awareness is IEM. There is no question of whose body this is, because there is no question of whom the chair affords sitting for. ("Here is an affordance, I wonder who it is an affordance for?" is not a question that makes sense.) The body as object - the body as it appears in the mirror test - is not IEM. But this lived body very much is.

\section{Pre-Reflective Awareness: A Criterion of Identity}

This is a situation that will be familiar to most who have a family dog. A dog sees, at some distance, another dog - one that it has met before. At this point, the dog's reaction whether excited, tense, playful, submissive, dominant, etc. - will depend, at least in part, on the nature of their previous encounter. This supposes that the dog remembers the other dog and their previous encounter. This may be semantic memory, or it may be episodic - there is substantial evidence for both sorts of memory in many species. But what, exactly, is it that the dog remembers? At a minimum, we should have to attribute the content this is familiar to the dog. Consider the relation between this content and the somewhat more complex content: I have seen this dog before.

The two contents are easily confused. Suppose one were in the habit of running these contents together - either assuming they are the same or thinking that it is not possible to have the former without the latter. Then one would be committed to denying the possibility of this sort of memory in any animal that does not have the ability to think thoughts about itself. That is, one would have to claim that memory of this sort is possible only in creatures with meta-cognitive abilities. This flies in the face of a weighty body of empirical evidence. The existence of semantic memory in animals is presupposed in many experimental protocols involving them. The existence of episodic memory has been demonstrated in several species, including not only the great apes but also animals such as rats and scrub jays (see Templer \& Hampton 2013 for a useful overview). If we are (i) willing to take this empirical evidence seriously, and (ii) unwilling to attribute meta-cognitive abilities to at least some of these animals, ${ }^{7}$ then it seems we have to accept that memory is more widely distributed than meta-cognition. If we accept this, then we have to find a way of keeping the two contents apart so that it is possible to remember this is familiar without also remembering I have seen this dog before. The answer I shall develop for this puzzle takes us to the heart of the idea of pre-reflective awareness, and the relation between it and reflective awareness.

Among those who believe in pre-reflective awareness, it is common to think that it is prereflective awareness that makes reflective awareness possible. This seems to be the view of Kant (1781/87), for example, and it is certainly the view of Sartre (1943). This idea forms the basis of the model of pre-reflective awareness I shall develop. 
Consider, again, the relation between the memory contents this is familiar and I have seen this dog before. If an individual has a memory with the latter content, then it must also have a memory with the former content. This need not be an explicit or occurrent memory, but it must exist at least in dispositional form - manifesting as a tendency to think and behave in certain ways rather than others. (If one were to ask a person whether the situation it is now visually presented with seems familiar, it would, if being truthful, respond affirmatively.) Therefore, having a memory with the latter content would guarantee having a memory with the former. The converse implication, however, does not in general hold. If an individual has a memory with the content this is familiar, it does not follow that it has a memory with the content I have seen this dog before. The individual need not have the latter memory even in dispositional form. To do so, further requirements must be met. Most obviously, the individual must have a meta-cognitive apparatus that allows it to think thoughts about itself. But when this apparatus is in place, the converse implication does hold: having a memory with the content this is familiar guarantees, at least in dispositional form, having a memory with the content I have seen this dog before. Let us call the additional features that are required so a memory with the former content guarantees a memory with the latter context, $\mathrm{C}$.

This gives us a way of understanding pre-reflective awareness. Roughly: an act of prereflective awareness is a function from contexts to an act of reflective awareness. Thus, when a creature has a memory with the content this is familiar, that creature is prereflectively aware of itself in virtue of the fact that this content, when plugged into an appropriate context - one comprising a milieu of meta-cognitive capacities - would guarantee that the creature also has a memory with the content I have seen this dog before.

Consider an individual, $I$. If $I$ thinks about itself, this thought will have what we can call $I$ content. Similarly, if this individual desires something for itself, this desire has I-content, and so on. An I-content is a content that contains an explicit representation of the individual - a first-person representation of the subject that entertains the content. Then, we can generalize this account of pre-reflective awareness as follows. $A$ is an act of pre-reflective awareness if and only if:

(1) $A$ has content ( $\neq$ I-content) and (2) for any individual, $I$, if $I$ has act $A$, and (3) $I$ has the relevant meta-cognitive abilities that constitute context $C$, then (4) $I$ must also have, at least in dispositional form, a state that has I-content.

By way of a concrete example, let's suppose that when the imagined dog remembers the other dog, it has a belief with the content this is familiar. This is not a state with I-content: the dog's belief is not about itself but about the other dog. Thus condition (1) is met. Let us also suppose that the dog does not have the relevant meta-cognitive abilities (i.e., the ones that form context $C$ ) required to think thoughts about itself. Nevertheless, it is also true that if the dog were to have those meta-cognitive abilities, then it would also have, at least in dispositional form, the belief with the content I have seen this dog before. Thus, conditions (2)-(4) are met. The dog has a belief (this is familiar). The dog does not have the meta- 
cognitive abilities required to think thoughts about itself. But if it did have those abilities, having the belief this is familiar would guarantee having the belief I have seen this before.

This general account of pre-reflective awareness as a function from contexts to acts of reflective awareness seems to fit the cases of perception, action and memory quite well. In perception, I am pre-reflectively aware of myself in that when visually presented with an object, I - a creature having the relevant meta-cognitive abilities - also have, at least in dispositional form, states (anticipations, expectations) with I-content. A creature that does not have the relevant meta-cognitive abilities, however, is still pre-reflectively aware of itself, for having such awareness is a matter of what would be the case if it were to have such abilities. When I see the chair as sit-able, then I am pre-reflectively aware of myself in the sense that seeing the chair in this way guarantees that I will have, at least in dispositional form, certain states that have I-content (e.g. "I can sit there!"). But, again, a creature that lacks my meta-cognitive abilities is still pre-reflectively aware of itself in virtue of the following subjunctive conditional: if it were to have the relevant metacognitive abilities, then it would also have to have a state with I-content. Finally, when I remember a person or situation as familiar, I am pre-reflectively aware of myself in virtue of the fact that I, the one who has the appropriate meta-cognitive abilities, must also have, at least in dispositional form, a state with I-content (e.g., "I have seen this before!"). But, when it encounters a situation or conspecific as familiar, a creature lacking in these abilities is still pre-reflectively aware of itself in virtue of the fact that, if it had the relevant metacognitive abilities, it would also have to have a state with $I$-content, at least in dispositional form.

\section{Reflective Awareness and the Unity of the Person}

Thus far I have marshaled some reasons for thinking that, in addition to reflective awareness there must be another kind of self-awareness: pre-reflective awareness. I have also supplied an account of this other form of awareness, in the form of a criterion that specifies under what conditions a creature will qualify as being pre-reflectively aware of itself. An opponent may grant all of this, but still resist the idea that animals - as subjects of pre-reflective awareness - are persons. This is because he insists that the form of selfawareness that is relevant to being a person is reflective self-awareness. I shall now argue against this claim. Not only is reflective self-awareness unnecessary for personhood, it can, in fact, never be the basis of personhood.

Recall that the task that reflective awareness was enlisted to achieve was accounting for the unity of a mental life. That there is a mental life of some sort going on inside the bodies of many animals is now widely accepted. The question is whether this mental life forms a unified whole. Reflective awareness is supposed to supply the required unity. I shall argue that this is precisely what it can't do. The argument, again, has a strongly Kantian flavor.

In the paralogisms, Kant developed some telling arguments against the idea that empirical apperception - a form of reflective awareness in the sense used here - can be the basis of the unity of the self. ${ }^{8}$ Here is one way of developing this idea - although I take no stand on whether it is what Kant had in mind. ${ }^{9}$ There is, let us suppose, a series of mental states and 
processes, and a question about whether or not this series forms a unified whole. The idea that reflective awareness can ground the unity of the series essentially involves introducing further (higher-order) mental states - for example, thoughts to the effect that the original (first-order) states all belong together, or belong to the same individual. The problem is that this strategy will work only if it is guaranteed that these higher-order states belong together with the first-order states and processes. We began with a question of unity. Adding more states can, logically speaking, only augment this problem: for we now face the question of whether these added states form a unified whole with the states they are supposed to unify.

This is a rather abstract exposition. To illustrate it more concretely, consider just four thoughts: (1) The sky is blue, (2) It will rain later, (3) I will take the boat to the island, and (4) I will go snorkeling early today. These thoughts could belong to one person or to different people. I might be thinking all four of these thoughts. Or I might be thinking (1) and (3) and you might be thinking (2) and (4), and so on. What could make all these thoughts belong to one person? According to the present suggestion, grounded in the idea of reflective self-awareness, the thoughts belong together because of another thought: a higher-order thought to the effect that thoughts (1)-(4) all belong together. But, since this higher-order thought is a different thought from these other ones, this merely raises the question of what makes this higher-order thought belong with the thoughts (1)-(4). If there is an issue about whether thoughts (1)-(4) belong together as thoughts all belonging to the same person, then this can hardly be solved by adding another thought. For the same issue must now arise about whether or not this further thought belongs with the other four.

This is a logical problem that afflicts the idea that we can account for the unity of a series of thoughts, or other mental states, by appealing to a further thought or thoughts. We can formalize this logical problem as follows. Suppose there are two series of mental states and processes, $A=\left[a_{1}, a_{2}, a_{3}, \ldots a_{n}\right)$ and $B=\left[b_{1}, b_{2}, b_{3}, \ldots b_{n}\right]$. There are also various higher-order thoughts to the effect that all and only members of the A-series and all and only members of the B-series belong together. That is, there exist higher-order thoughts $t_{1}, t_{2}, t_{3}, \ldots t_{n}$ of the following sort: $a_{1}$ belongs with $a_{2}, a_{3}, \ldots a_{n}, b_{1}$ belongs with $b_{2}, b_{3}, \ldots b_{n}$ and so on, for each $a$ and $b$. Will these higher-order thoughts unify the A and B series? They can do so only if they are themselves unified with the series they are supposed to unify. That is, each of $t_{1}, t_{2}, t_{3}, \ldots$ $t_{n}$ must be assigned to the correct series. If we simply assume that, say, $t_{1}$ is unified with $a_{1}$, $a_{2}, a_{3}, \ldots a_{n}$ then we are assuming the unity of the series $t_{1}+a_{1}, a_{2}, a_{3}, \ldots a_{n}$. But the unity of $a$ series of mental states and processes is precisely what we are trying to explain. At best, we have exchanged one question of unity - the unity of $\left(a_{1}, a_{2}, a_{3}, \ldots a_{n}\right)$ - with another: the unity of $\left(t_{1}, a_{1}, a_{2}, a_{3}, \ldots a_{n}\right)$. The problem of explaining the unity of the A-series has been replaced with the problem of explaining the unity of the A-series plus the higher-order state. This does not provide an answer to the question of unity; it presupposes such an answer.

There may seem to be an obvious response to this problem: the higher-order thought $t_{1}$ belongs with the A series $\left(\mathrm{a}_{1}, \mathrm{a}_{2}, \mathrm{a}_{3}, \ldots \mathrm{a}_{\mathrm{n}}\right)$ because it is about members of that rather than members of the B series. This suggestion will not work, however: it also smuggles in the unity of each series, just in a slightly less obvious way. Consider, again, the earlier example of thoughts (1)-(4). These form the A-series. Now let's introduce four further thoughts: (5) 
It may not rain after all, (6) I will snorkel for longer, (7) I hope to see some dolphins, and (8) Snappers are extraordinarily interesting fish. These thoughts form the B series. Thoughts (5) to (8) may be thought by the same person as thoughts (1)-(4) or they may be thought by someone else. If they are thought by the same person, then (1)-(8) do all belong to the same series. If they are thought by a different person, then we have two distinct series of thoughts: series (1)-(4) and series (5)-(8). The claim that a higher-order thought is about the series (1)-(4) and not the series (5)-(8) presupposes that we are dealing with two distinct series. But it is difficult to see how to make sense of the idea of the distinctness of two series without understanding what makes each a single, unified, series. If there is nothing that unifies (1)-(4) into one series, and (5)-(8) into another series, then there is no basis for thinking that (1)-(4) and (5)-(8) are distinct. The distinctness of two series, in this sense, presupposes the unity of each.

We can generalize this point. The claim that $t_{1}$ is about members of the A series and not the $B$ series presupposes that A and B series are distinct series of mental states and processes. Suppose this were not the case. Suppose, instead, that the labels " $A$ " and "B" merely picked out different parts of the same larger series. If this were so, then the higher-order thought $t_{1}$ would be about the B series also - because A and B are merely parts of the same series. Thus, to suppose that $t_{1}$ is about only members of the A series and not members of the $B$ series is to presuppose the distinctness of the two series. But the distinctness of two series presupposes unity. If there is nothing that unifies the A series into a whole and the B series into a distinct whole, then no sense can be made of the claim that the series are distinct.

\section{The Unity of the Animal Person}

The failure of reflective awareness to ground the unity of a mental life leaves us with two options. The first is to seek an objective basis for this unity: to understand the unity as grounded in some sort of physical structure such as the brain or body. Something like this might have been Kant's view. ${ }^{10}$ However, if a person is, essentially, nothing more than a physical structure such as a brain or body, the case for denying personhood to nonhuman animals dissipates - since they too have both. Hostility to the idea of animals being persons derives from the Lockean conception of the person, and the idea that self-awareness is necessary for personhood. Assuming - for the sake of argument - that the Lockean conception is correct, I have argued that we can distinguish two relevant forms of selfawareness and that the more familiar reflective form cannot provide a basis for personhood. In this section, I shall argue that pre-reflective self-awareness provides a much more promising basis for personhood. I shall try to make plausible the idea that the unity of a mental life can be grounded in pre-reflective awareness.

In attempting to explain the unity of a series of mental states and processes, I have argued that higher-order intentional states - of the sort involved in reflective self-awareness - can never be the ground or basis of the unity of a mental life, for they presuppose such unity. This failure is due to the fact that the higher-order state is distinct from the first-order state or states it is about. Once we accept this, the question of what unifies this higher-order state with the state or states it is about inevitably arises. And this means that attempting to 
explain the unity of a series of mental states and processes in this way - by the addition of a distinct higher-order state - will merely exchange one question of unity for another.

The fact that the root of the problem is the distinctness of an act of reflective self-awareness from the state or process that it is about allows us to see why pre-reflective self-awareness is a much more promising basis for the unity of a mental life. Unlike its reflective counterpart, pre-reflective awareness is not a separate act. Rather it is built into acts of conscious experience that are not, typically, about the self but about something else entirely: the book that I see as a book, the chair that I see as affording sitting, and so on. I see the book as a book only because I have generated various (implicit) expectations about how my experience will change in varying circumstances, and I am implicated in many of those expectations. In seeing a chair as sit-able, I am aware - pre-reflectively - of both my goal and my body. Pre-reflective self-awareness is, in this sense, not separate from these conscious acts of seeing but part of these acts. Thus, appealing to pre-reflective selfawareness in an account of the unity of a mental life does not engender the kind of regress we saw when appeal is made to reflective self-awareness. Because pre-reflective selfawareness is not distinct from first-order conscious acts, the question of whether it is unified with these acts does not arise.

The reflective model of self-awareness treats such awareness as a separate act - something added to an act of experience. Pre-reflective awareness, on the other hand, is built into the act of experience itself. In any conscious experience there is pre-reflective awareness of the "I" who has the experience. This is the ultimate basis of the unity of a mental life. Whenever a subject has experiences, it recognizes, pre-reflectively, that these experiences belong to it - because this is part of what it is to have conscious experience.

\section{The Pervasiveness of Personhood}

Personhood is typically regarded as an accolade worthy of bestowal only on the (selfappointed) crème of the animal kingdom: humans above a certain age, and possibly (although, here, one might have to hold one's nose) other hominids and cetaceans. Personhood, on this conception, is a notable intellectual achievement that comes only with reflective self-awareness. If the arguments of this paper are correct, then personhood is far more basic and hence far more pervasive than this. A person exists wherever there is a unified mental life. But the unity of a mental life is not something separate from that life, something added to it in the form of an additional act of reflective awareness. There is a certain sort of mental life that entails its own unity: to have this sort of mental life at all entails that this mental life is unified. The mental life in question is made up of what we might call experiencing as. Seeing something - a book or chair - as something (as a book, a chair, as sit-able, etc.) is a form of experiencing as. So too is hearing a sound as something and so on. Whenever we find experiencing as, we find pre-reflective awareness of the self. And whenever we find pre-reflective awareness of the self, we find a unified mental life. Personhood extends into the animal realm as far as experiencing as.

Many will find this conclusion incredible (or worse). If you are one of these people, fear not: there are always ways of resisting any conclusion. (The compelling of acceptance is not 
something that can be achieved through argument - for that, as David Lewis once noted, one would need not an argument but a magic spell). For example, one might deny (and some have ${ }^{11}$ that having a unified mental life is sufficient for being a person. But instead of thinking of all the ways in which animals might not be persons, or juggling with one's conception of a person to ensure that animals are disqualified, it might be more fruitful instead to think of the ways in which they are. If the arguments of this paper are correct, then many animals are the subjects of a unified mental life. And, if this is correct, then many animals are persons in at least one prominent - indeed, predominant - sense of that term.

Call for Commentary: Animal Sentience publishes Open Peer Commentary on all accepted target articles. Target articles are peer-reviewed. Commentaries are editorially reviewed. There are submitted commentaries as well as invited commentaries. Commentaries appear as soon as they have been revised and accepted. Target article authors may respond to their commentaries individually or in a joint response to multiple commentaries.

Instructions: http://animalstudiesrepository.org/animsent/guidelines.html

\section{References}

Andrews, K. (2011) Beyond anthropomorphism: attributing psychological properties to animals. In T. Beauchamp \& R.G. Frey (Eds.), The Oxford handbook of animal ethics (pp. 469-494). (New York: Oxford University Press)

Ari, C., \& D'Agostino, D. P. (2016) Contingency checking and self-directed behaviors in giant manta rays: Do elasmobranchs have self-awareness?. Journal of Ethology, 34(2), 167174

Baron-Cohen, Leslie, A., \& Frith, U. (1985) Does the autistic child have a "theory of mind"? Cognition, 21(1), 37-46

Benvenuti, A. (2016, in press) Evolutionary continuity and personhood: Legal and therapeutic implications of animal consciousness and human unconsciousness. International Journal of Law and Psychiatry.

Cupp, R. L. (2016) Focusing on human responsibility rather than legal personhood for nonhuman animals. Pace Environmental Law Review, 33(3), 517

Fitzgerald, E. A. (2015) [Ape]rsonhood. The Review of Litigation, Spring 34, 337

Gallup, G. G., Jr., \& Anderson, J. R., \& Shillito, D. J. (2002) The mirror test. In M. Bekoff, C. Allen, \& G. Burghardt (Eds.), The Cognitive Animal (pp. 325-334). (Cambridge, MA: MIT Press)

Gallup, G., Jr. (1970) Chimpanzees: Self-recognition. Science, 167(3914), 86-87 
Holmes, O. W. (1881) The Common Law. (New York: Dover Publications, 1991)

Hurley, S. (1998) Consciousness in Action. (Cambridge, MA: Harvard University Press)

Husserl, E. (1907) Things and Space. (Husserliana - Edmund Husserl, Collected Works, Book 7) (New York: Springer, 1997)

Kant, I. (1781/1787) Critique of Pure Reason. (London: Penguin, 2008)

Kaplan, D. (1989) Demonstratives. In J. Almog, J. Perry, \& H. Wettstein (Eds.), Themes from Kaplan (pp. 481-563). (New York: Oxford University Press)

Locke, J. (1690) An Essay Concerning Human Understanding. (London: J. M. Dent and Sons, 1961)

Mitchell, R. W. (2002). Kinesthetic visual matching, imitation, and self-recognition. In M. Bekoff, C. Allen, \& G. Burghardt (Eds.), The Cognitive Animal (pp. 345-351). (Cambridge, MA: MIT Press)

Noë, A. (2004) Action in Perception. (Cambridge, MA: MIT Press)

O’Regan, K., \& Noë, A. (2001) A sensorimotor account of vision and visual consciousness. Behavioral and Brain Sciences, 24(5), 939-73

Parfit, D. (1984) Reasons and Persons. (Oxford: Oxford University Press)

Penn, D., \& Povinellli, D. (2007) On the lack of evidence that non-human animals possess anything remotely resembling a theory of mind. Philosophical Transactions of the Royal Society $B, 362,731-744$

Povinelli, D., \& Vonk, J. (2003) Chimpanzee minds: suspiciously human? Trends in Cognitive Sciences, 4(4), 157-60

Prosin, N., \& Wise, S. M. (2014) The nonhuman rights project: Coming to a country near you. Global Journal of Animal Law, 2.

Sartre, J-P. (1943) Being and Nothingness (Trans. H. Barnes). (Oxford: Blackwell)

Shoemaker, S. (1968) Self-reference and self-awareness. The Journal of Philosophy, 65(19), 555-567

Templer, V., \& Hamilton, R. (2013) Episodic memory in nonhuman animals. Current Biology, 23(17), 801-806

Wittgenstein, L. (1953) Philosophical investigations (Trans. G. E. M. Anscombe; Ed. R. Rhees). (Oxford: Blackwell) 
${ }^{1}$ In 1999, New Zealand prohibited the use of five great ape species in research and teaching, a move that has been interpreted as giving these species weak legal rights. Several European countries have banned the use of great apes in animal testing. In 2007, Spain's Balearic Islands passed legislation that, in effect, grants legal personhood to all great apes. In 2014, Argentina granted basic human rights to a captive orangutan. In April 2015, the New York Supreme Court ordered a writ of habeas corpus for two chimpanzees, although the words "writ of habeas corpus" were removed in a subsequent ruling. (See Benvenuti 2016; Cupp 2016; Prosin \& Wise 2014; Fitzgerald 2015.)

${ }^{2}$ As Oliver Wendell Holmes, Jr., put it: "The life of the law has not been logic; it has been experience. The felt necessities of the time, the prevalent moral and political theories, intuitions of public policy, avowed or unconscious, and even the prejudices which judges share with their fellow-men, have had a good deal more to do than syllogism in determining the rules by which men should be governed. The law embodies the story of a nation's development through many centuries, and it cannot be dealt with as if it contained only the axioms and corollaries of a book of mathematics" (Holmes 1881, p. 1).

${ }^{3}$ It almost certainly bifurcates into many different forms, but there is one distinction - and consequently, two contrasting forms - that is of interest in this paper.

${ }^{4}$ It is a hotly contested matter what qualifies as evidence and how compelling it is. Thus, for many, the term "although" may be a little strong (it is for me). It can, alternately, be read as "even if."

${ }^{5}$ Although my opinion, for what it's worth, is that the "logical problem" is merely another iteration of the problem of other minds. Exactly the same argument could be applied to human beings.

${ }^{6}$ This argument has a Kantian inspiration: Kant thought there was a kind of awareness of the self that is implicit in understanding that successive appearances are appearances of one and the same thing. To experience the object as a persisting, unified thing, I must also experience myself as a persisting, unified thing. He called this the transcendental unity of apperception. I take no stand on whether the argument I present is what Kant had in mind. A more recent source for this sort of argument can be found in the work of Husserl (especially 1907). The account can also be found in the early pages of Sartre (1943). More recently the role of anticipation in seeing has featured prominently in enactive or sensorimotor accounts of visual experience. See O’Regan and Noë (2001) and Noë (2004). However, in none of these places, as far as I am aware, do we find this specific argument for the kind of implicit self-awareness that I am calling pre-reflective awareness. ${ }^{7}$ I should remind the reader that the claim that animals lack meta-cognitive abilities is one that I assume simply for sake of argument.

8 "The paralogisms of pure reason" is a chapter in Kant's rather large and difficult book, Critique of Pure Reason. The chapter is a sustained critique of the idea of inner sense or empirical apperception.

${ }^{9}$ It is also, at the very least, closely related to what Susan Hurley (1998) seemed to have in mind with what she called the "just more content" objection to subjective accounts of the unity of the self.

${ }^{10}$ According to Kant, however, this objective basis would have been noumenal rather than phenomenal.

11 Most notably, perhaps, see Parfit (1984). 


\section{"I Am Not an Animal!" \\ The Signature Cry of Our Species

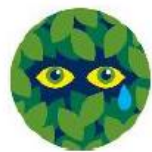

ur fellow animals and the Earth are under increasing threat from human activities. Anthropogenic climate change, habitat destruction and an unfolding mass extinction all beg the key question: Why are we incapable of changing our behavior?

At this unique two-day symposium, we look at how our behavior is driven psychologically by the need to see ourselves as separate from and superior to the rest of nature. And we ask why we need to keep telling ourselves, through our actions and belief systems, that "I am not an animal!"

We explore this exceptionalist view of ourselves with leaders in the fields of psychology, ecology, ethics, philosophy, law and advocacy. And we discuss how we can apply their insights to environmental and animal protection efforts.

\section{WHEN}

February 24-25, 2017

\section{WHERE}

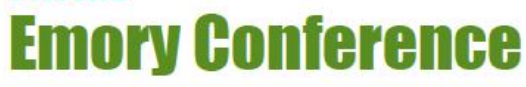
Center

1615 Glifton Road NE, Atlanta, GA 30329

Organized by Lori Marino, John Schacke, MichaeIMountain

REGISTRATION \& FULL INFORMATION www.not-an-animal.org
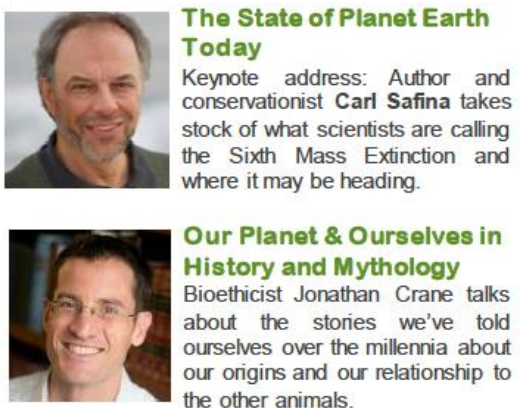

Our Planet \& Ourselves in History and Mythology Bioethicist Jonathan Crane talks about the stories we've told ourselves over the millennia about our origins and our relationship to the other animals.

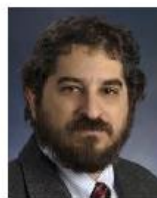

How We "View" Other

Animals

Randy Malamud, Prof. of English, Georgia State University, author of Reading Zoos, discusses the psychology of keeping animals in zoos, aquariums and circuses.

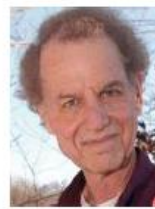

Some We Love, Some We Hate, Some We Eat

Hal Herzog, author, Emeritus Prof. of Psychology, Western Carolina University, explores the confusing relationships we have with different kinds of animals.

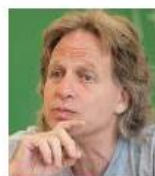

The Worm at the Core Sheldon Solomon, author and Prof. of Psychology, Skidmore College, explains how our College, explains how our
civilization and culture act as a defense against the anxiety we feel about our mortal, animal nature.
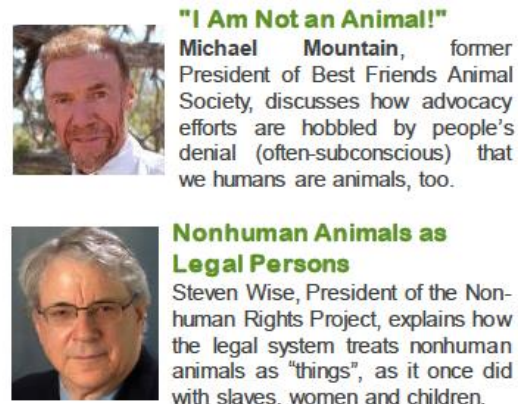

Nonhuman Animals as Legal Persons

Steven Wise, President of the Nonhuman Rights Project, explains how the legal system treats nonhuman animals as "things", as it once did with slaves, women and children.

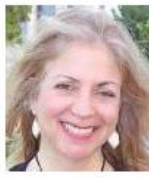

Someone, Not Something Lori Marino, Director of The Kimmela Center for Animal Advocacy, talks about how we are coming to see other animals as "someone" rather than "something" - as individuals in their own right.

Group Discussion

What do these insights indicate for environmental and animal protection efforts?

\section{SAHEDULE \& DETAILS}

www.not-an-animal.org 